\title{
The social embeddedness of academic online groups as a norm generating structure: A test of the Coleman model on norm emergence
}

Citation for published version (APA):

Matzat, U. (2004). The social embeddedness of academic online groups as a norm generating structure: A test of the Coleman model on norm emergence. Computational \& Mathematical Organization Theory, 10(3), 205226. https://doi.org/10.1023/B:CMOT.0000045369.98848.71

DOI:

10.1023/B:CMOT.0000045369.98848.71

Document status and date:

Published: 01/01/2004

Document Version:

Publisher's PDF, also known as Version of Record (includes final page, issue and volume numbers)

Please check the document version of this publication:

- A submitted manuscript is the version of the article upon submission and before peer-review. There can be important differences between the submitted version and the official published version of record. People interested in the research are advised to contact the author for the final version of the publication, or visit the $\mathrm{DOI}$ to the publisher's website.

- The final author version and the galley proof are versions of the publication after peer review.

- The final published version features the final layout of the paper including the volume, issue and page numbers.

Link to publication

\footnotetext{
General rights

- You may freely distribute the URL identifying the publication in the public portal. follow below link for the End User Agreement:

www.tue.nl/taverne

Take down policy

If you believe that this document breaches copyright please contact us at:

openaccess@tue.nl

providing details and we will investigate your claim.
}

Copyright and moral rights for the publications made accessible in the public portal are retained by the authors and/or other copyright owners and it is a condition of accessing publications that users recognise and abide by the legal requirements associated with these rights.

- Users may download and print one copy of any publication from the public portal for the purpose of private study or research.

- You may not further distribute the material or use it for any profit-making activity or commercial gain

If the publication is distributed under the terms of Article 25fa of the Dutch Copyright Act, indicated by the "Taverne" license above, please 


\title{
The Social Embeddedness of Academic Online Groups in Offline Networks as a Norm Generating Structure: An Empirical Test of the Coleman Model on Norm Emergence
}

UWE MATZAT

Sociology Section, Department of Technology Management, Eindhoven University of Technology, P.O. Box 513, 5600 MB Eindhoven, The Netherlands

email:u.matzat@tm.tue.nl

\begin{abstract}
This paper analyzes two questions. First, under which conditions does a norm emerge in academic online groups that prescribes members to help others during group discussions? Second, what effects does such a norm, and other social conditions, have on the contributing behavior of researchers during online discussions? It is argued that the Coleman model (1990) on the emergence of norms points to an important condition that facilitates the realization of such a norm. According to the Coleman model (1990) a dense network among members of a group tends to strengthen a group norm. The paper makes a distinction between different kinds of academic online groups. The criterion of the distinction is the extent to which within the membership a highly integrated research community exists. An online group with a highly integrated research community is called to have a high degree of social embeddedness of its online communication in offline networks. It is hypothesized that a high degree of embeddedness has a number of effects. A higher degree of embeddedness leads to a stronger help-prescribing norm. The stronger the norm the more researchers send online answers to questions of their co-members during public online discussions. Furthermore, a high degree of embeddedness increases the answering behavior of researchers directly because it provides opportunities to gain reputation within the academic community through contributing to the discussion. The study makes use of data that consist of a combination of survey data and observed data of the communication behavior of researchers in about 50 international academic emailing lists. The results provide evidence for the expected effect of embeddedness on the strength of the norm and for the effect of embeddedness on the answering behavior of researchers. The strength of the help-prescribing norm indirectly influences the answering behavior.
\end{abstract}

Keywords: norm, online community, social network, Coleman, academic communication, internet

\section{Introduction}

Many academic and non-academic internet users are members of online groups, such as emailing lists (Horrigan, 2001; Matzat, 2004). Researchers as members of online groups can gain information as well as new contacts to other researchers (ibid.). The attainment of the benefits, however, is dependent on sufficiently motivated co-members who are willing to contribute to the public online discussion of the group and willing to provide help to others who asked for help. The application of advanced technology alone does not guarantee that members spend time and effort for becoming active contributors. The problem of how to 
motivate members to become active in online discussions is a serious one that many online groups do not solve (Cummings et al., 2002). Since every member can profit from the discussion in an online group independently of his own intensity of contribution, a free rider problem can emerge (Kollock, 1998).

Some argue that the problem could be solved by norms that would motivate members to contribute (McLure Wasko and Faraj, 2000). I regard the normative solution just as a shift of the problem from "how to motivate members?" to "how to foster the emergence of a norm?". Only when the second problem is solved, the normative solution can be considered as useful.

This paper contributes to answering the question of which conditions facilitate the emergence of a norm that prescribes members of academic online groups to contribute to online discussions by answering the questions of other members. Furthermore, it analyzes what the behavioral effects of such a norm are and what other conditions motivate members of academic online groups to contribute to online discussions by answering questions.

It is often argued that relationships offline would affect online interaction (see e.g., Wellman and Gulia, 1998; Wellman, 1997). While this may be true, it remains open how (if at all) this happens. It is unknown by what mechanisms offline relationships influence online interaction. This paper specifies potential mechanisms, derives a number of hypotheses, and tests them. The arguments, in a nutshell, are as follows. Academic online groups are distinguished according to the extent of integration of the membership as a research community. In some online groups members, not necessarily all, constitute a highly integrated research community that interacts offline. This is called a high degree of social embeddedness of the online group in a research community. The claim is that a high degree of social embeddedness has a number of effects. It facilitates the emergence of a help-prescribing norm since online groups with a high degree of embeddedness have a higher network density which fosters norm development (Coleman, 1990). The existence of a strong norm, as well as a high degree of embeddedness, provide incentives for researchers to become active during online discussions as a provider of help and answers. Under both conditions researchers can gain reputation through active discussion contributions.

The paper contributes to filling two gaps in the field of internet research. First, if makes clear by what mechanisms offline relationships could influence online interaction. Second, it points to an important institutional condition, namely the embeddedness of an academic online group in a research community, that could influence what the outcomes of online groups for its members are (see DiMaggio et al., 2001).

The paper is built up as follows. Section 2 presents the underlying theory. In Section 2.1 the Coleman model (1990) of the emergence of norms is presented. Section 2.2 presents the so-called reputation model. This simple price-theoretical model argues that under specific conditions researchers are motivated to contribute answers to online discussions because it gives them reputation in the academic community. Both models are used to derive a number of hypotheses about norm emergence and the effects of a help-prescribing norm. Section 3 describes the design of the study, some measurements, and descriptive findings. Section 4 presents the results of the data analyses that test the hypotheses. Section 5 summarizes the arguments and findings, and draws conclusions for further research on the social impact of information \& communication technology (ICT). 


\section{The Emergence and Effects of Norms in Online Groups: The Coleman Model and the Reputation Model}

In the following, first the Coleman model (1990) is used as an explanation of the emergence of norms in academic online groups. Thereafter, Section 2.2 uses a simple price-theoretical model to explain under which conditions researchers are motivated to contribute answers to the questions of co-members during online discussions.

\subsection{The Social Embeddedness of Online Groups as a Norm Generating Structure}

Coleman (1990) offers a two-step explanation for the emergence of norms in a group of actors. First, he explains under which conditions group members realize the need for the existence of a norm, calling this a 'demand for norms'. Second, this demand has to be 'satisfied'. That is, the group members' wish of establishing a norm is not yet enough, but it must be converted into rules that are followed by the members.

A norm is seen as a rule that prescribes a specific kind of action (or proscribes another). A norm concerning this specific action exists to the degree that there is a consensus within the group, implying that the right to control this action is held not by the actor himself but by others (ibid., p. 243). Stated differently, a norm is not a property of a group member, but a property of the whole group. When will demand for such a consensus arise?

Coleman argues that demand for a norm concerning a specific action, the focal action, will arise under two conditions. First, the focal action has similar positive or negative external effects on the interests of other group members. Second, in the group there exists no opportunity to exchange rights of control of the action. The externalities awaken the interests of other actors to control the focal action. If the second condition is not fulfilled, group members can conduct bi- or multilateral exchanges to profit from the positive externalities or to avoid the negative ones. In this case a need for group consensus no longer exists. If the interests in the external effects of the focal action are sufficiently large and no market for exchange exists, demand for a norm emerges. The norm, however, is a collective good for the beneficiaries, since everybody profits from it independently of whether he contributes to its maintenance. When will the demand for a norm be satisfied?

Such a demand will be satisfied, Coleman (1990: chapter 11) argues, if the actor transfers his right of control of his action to the other group members. For such a transfer the employment of positive or negative sanctions is necessary, or else the group member has no incentive to do something that is of interest to others but not directly to him. The employment of sanctions, again, is a public good for the members. Every member profits from the norm independently of whether he bears the sanction costs. Coleman states that demand for a norm will be satisfied when this public good problem has been solved. When does this happen?

This happens when the network of social relations between the group members is sufficiently dense to allow for joint actions to employ sanctions (Coleman, 1990, p. 273ff). The existence of a sufficiently dense network would offer opportunities for employing sanctions or encouragement in an easy way. "Because social relationships consist of obligations and expectations, ..., and because each actor continues to control some events in which the 
other is interested, there exists ... leverage which can be used for the purpose of developing sanctions" (Coleman, 1990, p. 270). The existence of externalities of an action and the existence of a sufficiently dense network between the members who profit from these externalities are therefore the crucial conditions for the emergence of a norm, given that no opportunities for individual exchanges exist.

The above conditions apply to an academic emailing list with a sufficiently high degree of embeddedness in an integrated research community. A contribution to the discussion through the sending of a useful public answer has positive externalities for the members. If the topic of the emailing list is strongly linked to an offline academic community, there will be some interest in the discussion and therefore in contributions. A market for the individual exchange of answers does not exist in large emailing lists. Thus, informal rules that prescribe some degree of active participation and the provision of help to other members are welcome. Such rules will be realized in emailing lists with a sufficiently high degree of embeddedness. If an emailing list is embedded in a well-integrated research community that shares many interests and activities in common, then the informal network of the group members has a high density. If the active researchers of an emailing list meet regularly at conferences and other meetings, then plenty of informal communication takes place between them. Such informal communication presents opportunities for a researcher to stimulate a colleague to answer questions on topics he is an expert in. For example a side-remark in a bilateral email communication might refer to the discussion or to an open question within an emailing list. The same might happen in informal conversations among small groups of researchers during meetings.

One should therefore expect that in emailing lists with a sufficiently high degree of embeddedness, a norm that prescribes the provision of help by sending public email answers emerges. These insights can be summarized in the following hypothesis.

Hypothesis 1: The higher the degree of embeddedness of the emailing list in a well-integrated academic research community, the more likely is the emergence of a help-prescribing norm in the emailing list.

\subsection{The Members' Contributing Behavior to Online Discussions}

In Section 2.2.1 the so-called reputation model is briefly presented and used to derive a number of hypotheses about conditions that favor the answering behavior of researchers during online discussions. An additional point is that the reputation model allows developing hypotheses about the effects of a help-prescribing norm. This is done in Section 2.2.2.

2.2.1. The Reputation Model. The reputation model uses Becker's (1976) theory of social interaction. According to the reputation model, researchers aim at maximizing their status. Their activities are subgoals or means for status maximization (Lindenberg, 1986). In this paper, the focus only is on the attainment of academic reputation $(\mathrm{Z})$ within the academic community as a means of status attainment. ${ }^{1}$ The means for a researcher to gain reputation within his academic community - be it online or offline-is not only to solve academic problems as part of his customary academic activity $(X)$, but also to make his academic 
community aware of his competence $(R)$. The competence awareness of the community naturally depends to a large degree on the prominence that the researcher already has. This is the basic degree of competence awareness he is already equipped with $\left(D_{i}\right)$ (Becker, 1976). Additionally, in varying degrees the competence awareness is dependent on the sending of public answers $(h)$ to questions of others during online discussions.

The crucial idea of the reputation model is the following. Under some conditions, providing help to other researchers by sending public email answers to their questions in the view of all other colleagues who use the emailing list can be a means of enhancing the collegial awareness of the researcher's competence. It is a way of gaining some reputation within the community. While the reputation is obtained by online activities, its usefulness to the researcher is not restricted to the online world.

The argument rests on findings of social exchange theory showing that the pattern of help and consultation among colleagues in working groups is characterized by an exchange of help for status (Blau, 1955, 1964). The degree of social interaction within an online group, however, is usually not as large as in "real" working groups. Therefore, in general little reputation (and thus status) can be gained by providing help to other members of an emailing list.

Nevertheless, some conditions enhance this gain of reputation and can therefore make this means more efficient for the production of reputation. The most important of these conditions is a high degree of social embeddedness of the emailing list. The embeddedness consists of the frequency of the members' social interaction with each other as a research community outside of the context of the emailing list. The more the group of researchers in the emailing list constitutes an integrated research community that shares many interests and activities in common, the higher is the degree of embeddedness. A high degree of embeddedness makes the electronic activities in the emailing list visible to the whole research community. The higher the degree of embeddedness of the emailing list, the more giving the right answers is a suitable means of showing that one is a competent member of the academic community. Often the questions discussed within emailing lists are ordinary problems for certain researchers who face them regularly in their research field. Nevertheless, an academic can show to others by reacting to a question that this sub-field is still an important part of his research schedule that is given some priority because he spends some of his scarce time on it to help others. He also shows by quickly sending a short email that he has the competence to answer these questions easily.

When a question has been sent to the emailing list, the researcher has to make a decision. He must choose between pursuing his customary academic activity $(x)$ and obtaining more public awareness of his competence $(R)$ by sending public email answers $(h)$ to the emailing list as a means to gain reputation within his academic community $(Z)$. These ideas can be formalized according to the theory of social interaction (Becker, 1976) to find out how this decision is influenced by a number of conditions.

In its simplest form the theory of social interaction assumes that actors $i$ get some utility $U$ by striving for a single commodity $Z$ that is produced by a single good $x$ and a single characteristic $R$ that describes a property of other persons (Becker, 1976),

$$
U_{i}=Z(x, R) .
$$


According to the reputation model for the attainment of reputation $(Z)$ a researcher not only needs to generate some research results by way of customary academic activities $(x)$, but he also needs to obtain awareness of his competence in his academic community $(R)^{2}$

$$
Z=f(x, R)
$$

The total degree of competence awareness $(R)$ that a researcher obtains can be divided into a part that depends on his efforts within his emailing list in providing answers $(h)$ to questions and into a part consisting of the awareness he is already endowed with $\left(D_{i}\right)$.

$$
R=D_{i}+h
$$

The researcher can use his time for pursuing a general academic activity $x$ which costs him on the average some time $P_{x}$. Alternatively, he can spend his time on sending email answers to the emailing list leading to more immediate competence awareness $R$ and costing on average some time $P_{R}$. His time budget constraint $(I)$ for the decision whether to spend his time on customary academic activity $(x)$ or on the provision of public online answers (h) can be written as

$$
P_{x} x+P_{R} h=I_{i},
$$

where $P_{x} x$ represents the total amount of time spent on general academic activity and $P_{R} h$ represents the total amount of time spent on writing and sending an email answer to the emailing list.

A researcher's social income $S_{i}$ for the production of reputation not only consists of the amount of time $I$ he can currently spend on $x$ and $R$ for the production of reputation, but also of the time value of his endowment with competence awareness $P_{R} D_{i}$.

$$
S_{i}=I_{i}+P_{R} D_{i}
$$

The researcher maximizes his reputation if he chooses a combination of input factors $x$ and $R$ in such a way that the ratio of their marginal products is equal to the ratio of their marginal prices (Hirshleifer and Glazer, 1992). This is expressed by the following equation that presents the conditions that must be fulfilled for the decision to maximize status, namely

$$
\frac{\text { marginal product } x}{\text { marginal product } R}=\frac{\text { marginal price } P_{x}}{\text { marginal price } P_{R}} \text {. }
$$

In addition, the researcher takes into account his time constraints (4) and his given endowment with collegial awareness of his competence (Eq. (3)) both of which are summarized in Eq. (5). Accordingly, for the analysis of the decision whether to send an email answer one must investigate what influences the shape of the budget line (4), and the shape of the output 
curves, that is, the relative marginal products and the relative marginal prices summarized in Eq. (6). This is done next.

For list members with little email experience there are extra costs involved in answering questions. Members with little email experience need more time for presenting their competence in a favorable way to a whole group of researchers with specialized norms of conduct. This price effect can be divided into an output and a substitution effect. An experienced email user will tend to substitute more answered emails $(h)$ for customary academic activity $(x)$ than an inexperienced user, since the relative price $P_{R}$ for the experienced user is lower. Moreover, an experienced user can answer more emails than an inexperienced user in the same time, saving time to be spent additionally on $x$ and $R$. Not only the substitution effect but also this output effect leads to an increase in the number of answered emails for the experienced user. Both effects increase the tendency to answer for experienced users.

Whereas for an inexperienced email user the time spent on one publicly sent email is higher and therefore $P_{R}$ is higher, other conditions influence the relative marginal product of sending public email answers. That is, they offer the opportunity for acquiring a larger degree of competence awareness with the same number of sent email answers.

One crucial condition that varies between different emailing lists is the degree of social embeddedness. The more the group of researchers in the emailing list shares interests and activities in common as an integrated research community, the more a researcher gains awareness of his competence and thereby reputation in the whole academic community by sending public email answers. The higher the degree of embeddedness, the higher is the likelihood that a researcher will become active in the emailing list as a provider of help and answers.

A naive expectation might be that the effect of embeddedness should be larger for those who have more experience in sending email and thus need less time for using the opportunity. However, the reputation model makes exactly the opposite prediction. The concept of the elasticity of substitution can be used to derive a negative interaction effect between email experience and embeddedness. The lower the degree of embeddedness, the lower is the marginal product of sending public email answers. The less relevant the sending of public email answers for gaining reputation, the more easy it is to find substitutes for this method of reputation attainment if the costs for this activity increase (see e.g., Hirshleifer and Glazer, 1992; Baumol, 1977, p. 88). As a consequence, the higher the degree of embeddedness, the smaller the price effect is. The reputation model predicts that the effect of email experience should be larger under a low degree of embeddedness (see figure 1).

In addition, the opportunities for the attainment of competence awareness are increased by the existence of personally known colleagues (e.g. important departmental colleagues, collaborators within one's informal network) within the emailing list. The existence of colleagues enables the researcher to gain more awareness of his competence because one notices and remembers much better useful contributions made by acquaintances and near colleagues. Researchers who know about the existence of personally known colleagues within their emailing list thus have a higher probability of contributing to the discussion by answering questions. 


\section{price $\mathbf{P}_{\mathbf{R}}$}

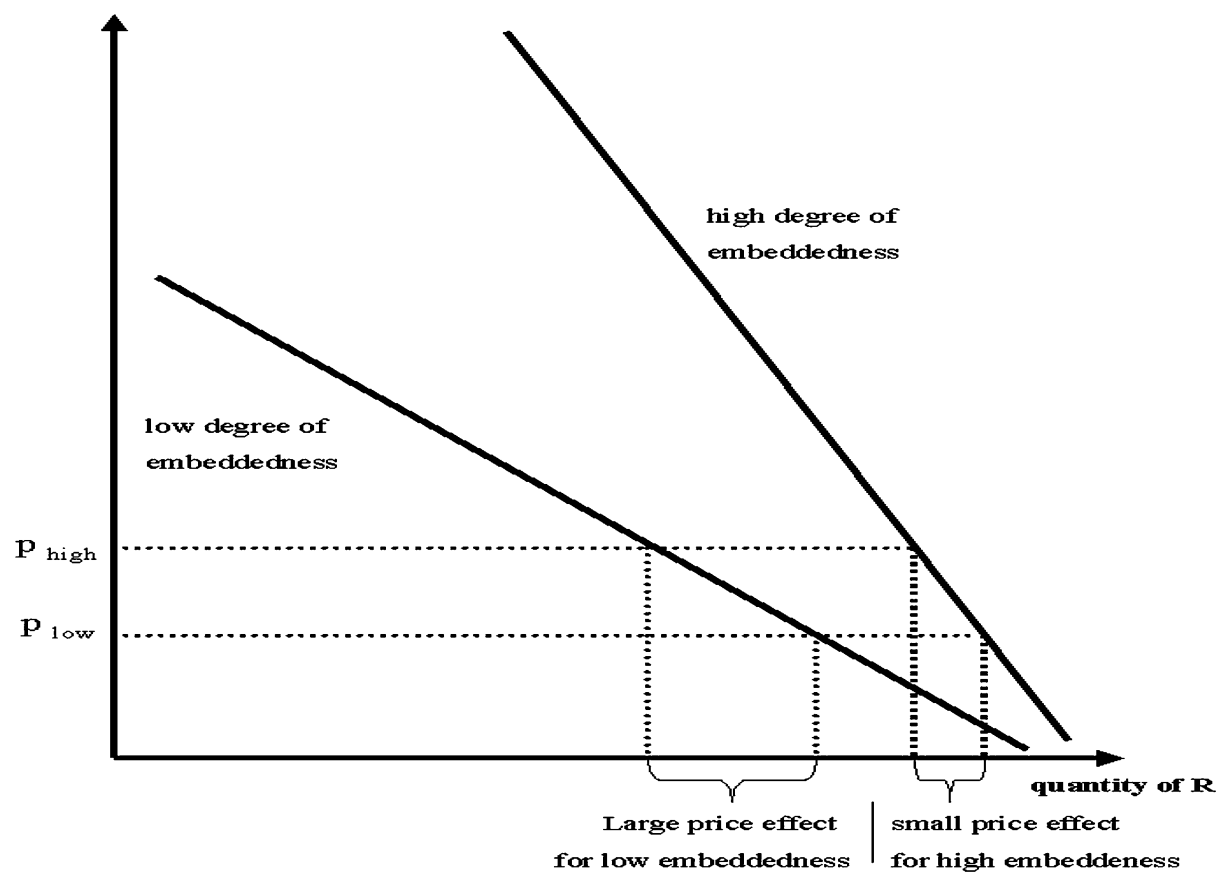

*:exact shapes and distances between the input curves arbitrary

Figure 1. Aggregated demand for input*.

Researchers with an already established high status are endowed with a larger degree of awareness of their competence than researchers with a lower status ( $\left.D_{\text {high-status }}>D_{\text {low-status }}\right)$. For them the relative marginal product of $R$ for the attainment of reputation $(Z)$ and thus status is lower, because they have already acquired a high degree of collegial awareness of their competence $R$. This negative endowment-income effect results in a smaller degree of purchased online awareness within the emailing list $\left(h_{\text {high-status }}<h_{\text {low-status }}\right)$. The higher the status of a researcher, the lower is the probability that he will send an email answer to the emailing list.

Finally, in emailing lists the degree of reputation $(Z)$ gained by a public answer is higher when the number of group members with a high status within the academic community is larger. If one gains some collegial awareness within a more prestigious group of researchers, this leads to a larger degree of acquired reputation. Accordingly, due to the larger marginal product of awareness, in such groups members should have a greater propensity to answer questions in public.

The arguments of the model can be summarized in the following figure 2 that shows the effects of email experience, embeddedness, and number of colleagues in the emailing list. 


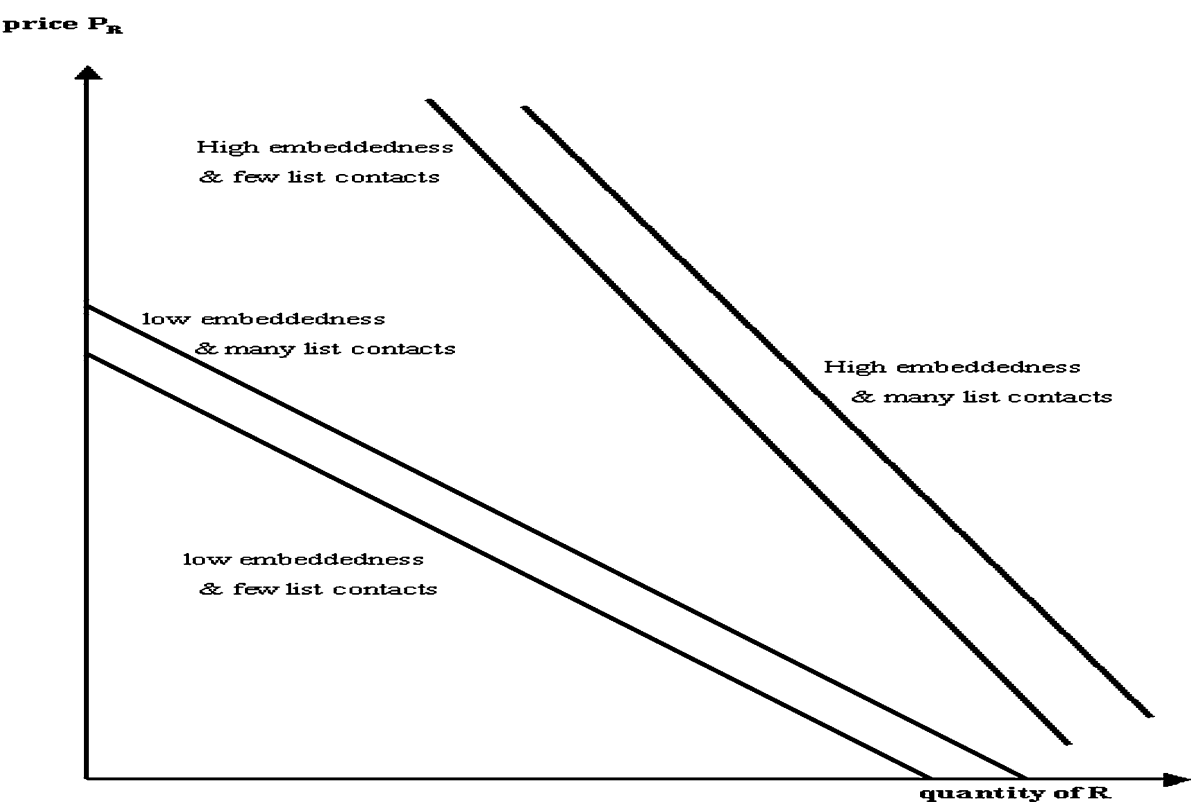

*: other effects have been omitted for simplicity (exact shapes and distances between the input curves arbitrary)

Figure 2. Aggregated demand for input dependent on email experience, embeddedness, and number of emailing list colleagues*.

As a summary, the following hypotheses have been derived.

Hypothesis 2: The more experience the researcher has with the use of email, the higher the probability that the researcher sends public answers to questions in the emailing list.

Hypothesis 3: The higher the degree of embeddedness of the emailing list, the higher the probability that the researcher sends public answers to questions in the emailing list.

Hypothesis 4: Under a high degree of embeddedness of the emailing list, the effect of email experience will be smaller than under a low degree of embeddedness.

Hypothesis 5: The more personal colleagues the researcher has in the emailing list, the higher the probability that the researcher sends public answers to questions in the emailing list.

Hypothesis 6: The more prominent the researcher, the smaller the probability that the researcher sends public answers to questions in the emailing list.

Hypothesis 7: The higher the number of very prominent researchers as members, the higher the probability that a researcher sends public answers to questions in the emailing list.

2.2.2. The Effects of a Help-Prescribing Norm. The effects of a help-prescribing norm can be derived by using the insights of the reputation model. First, the existence of a 
help-prescribing norm increases the importance of sending public email answers for the attainment of reputation. If a strong norm exists then the research community regards online participation as an important kind of activity that should be encouraged. The public provision of help by sending useful answers attracts more attention if there is a strong consensus about the beneficial effects of sending adequate answers. In such groups the sending of adequate public answers is an even more respectable way of presenting one's competence and will provide more attention and reputation $(Z)$ within the academic community, than in groups without such a consensus. The effect of the increasing marginal product of the sending of public email answers is that researchers will adjust their activities by spending a bit more time on the public provision of help to others.

In addition, a second effect can be derived. Once again, if emailing lists differ with regard to the marginal product of sending public email answers, then the price effect of increasing experience of email use should be smaller in emailing lists with a helpprescribing norm than in emailing lists without such a norm (compare the arguments for figure 1).

Researchers in emailing lists without a help-prescribing norm will find it easier to adjust their bundle of activities to a high relative price, since it is easier to find a substitute for a reputation-providing activity if the activity is less relevant for the provision of reputation. The elasticity of substitution is smaller if the marginal product of the activity is greater (see Hirshleifer and Glazer, 1992, p. 131). In emailing lists with a weak help-prescribing norm the effect of email experience should be larger than in emailing lists with a strong help-prescribing norm. The insights can be summarized in the following hypotheses.

Hypothesis 8: The stronger the help-prescribing norm in the emailing list, the greater the likelihood that the researcher will send a public email answer to the emailing list.

Hypothesis 9: In emailing lists with a strong help-prescribing norm, the effect of email experience on the sending of public email answers will be smaller than in emailing lists without such a norm.

The hypotheses are to be tested under ceteris paribus conditions. Pro-social attitudes/ group attachment also could play motivational roles in becoming an active participant in an online discussion (Kollock, 1998; Constant et al., 1994). Time restrictions of the members (Ekeblad, 2001) may be important. One also should control for possible problems related to accessing the online group. Some studies suggest that gender differences (Herring, 1999), the formal position, research experience and knowledge about the topic influence whether researchers become active (Lewenstein, 1995). It may make a difference whether a researcher is a native speaker of the relevant language. In addition, one should control for the number of questions that have been sent in the past to the online group, which may influence whether a researcher becomes an active help provider in the group. The communication habits of some emailing lists suggest that a public discussion of questions should not always take place in the online group. Some emailing lists wish to avoid such discussions by setting the "default reply-to" function in the appropriate way. Moreover, for testing the hypothesis of the Coleman model on the emergence of a norm one should take into account the time duration of the interaction (see e.g., Walther, 1996) as well as other factors. 


\section{Design of the Study, Measurements, and Descriptive Findings}

\subsection{General Design and Method of Data Analysis}

There are two different kinds of data used for the tests of the hypotheses. First, the communication behavior of members of 49 academic emailing lists was observed. In May and June 1999 all the emails that were publicly sent to these 49 mailing lists were collected. These data include the information about the participation behavior of researchers. Second, a random sample of all active and passive members of the 49 mailing lists were sent an online questionnaire in order to obtain the information needed for the measurement of the theoretical concepts. Both kinds of data were combined into one data set with the help of the email addresses of the respondents. As a result, the combined data set contains information about the (non-)participation behavior of the researcher and about his background, his social network, his academic community, etc.

The 49 mailing lists were selected in the following way. In the first step, a "paperand-pencil-questionnaire" was sent to a random sample of English and Dutch university researchers in eight different disciplines in the humanities, the social sciences, and the natural sciences. Every respondent to this questionnaire who was an emailing list user was asked to fill in information about the five most important emailing lists that he used for his research. This resulted in a list of mailing lists used by a random sample of university researchers, out of which a random sample of 49 mailing lists was selected. ${ }^{3}$

The sample size of the used data set is 4562 , which corresponds to a response rate of $35.1 \%$ of all 12996 randomly selected active and passive members who were subscribed in the middle of April 1999 to at least one of the 49 mailing lists. The proportion of active participants, that is those who sent at least one email to their emailing list during the two months of observation, among all 12996 selected members is 7.9\%. Among the respondents the proportion of active participants is $11.2 \%$, which is slightly higher. The sample thus has a slight bias in favor of active participants. The bias is disturbing, but need not be a fundamental problem. Additional data analyses (Matzat, 2001) suggest that the slight bias does not influence the conclusions drawn from the data analysis.

The main analysis methods consist of multiple linear and logistic regression analyses. Since the data is clustered, however, there are a number of violations of the standard regression model (Snijders and Boskers, 1999). This clustering is taken into account by using a two-level multiple regression analysis. All statistical models include a number of control variables, as summarized in the theory section. ${ }^{4}$

\subsection{The Measurements}

3.2.1. The Strength of a Help-Prescribing Norm in the Group. The existence of a group norm that prescribes the provision of help and answers by researchers was measured with the help of a Mokken scale analysis (Mokken, 1997; Molenaar, 1997). A number of statements were presented only to those members of a mailing list who a) had been a member for at least one year and who b) had actively been doing research in the field that is most closely related to the mailing list for at least 2 years. These members were asked to assess the applicability to their mailing list of three statements. The statements indicated to what extent the provision 
of help and answers is related to sanctions in the group. The underlying assumption is that the stronger the sanctions, the stronger is the norm in the group (Coleman, 1990).

"In this Mailing List researchers encourage each other to give answers to questions that they have knowledge about." "Individual members can develop a reputation for their regular provision of useful answers to questions in this Mailing List." "Members of this Mailing List expect individual researchers known for their competence to give answers to stated questions." The answering options varied in 6 steps from "disagree completely" to "agree completely." The analysis of the effects of the norm takes the mean of the scale values of the mailing list members as an indicator for the strength of the norm in the group, since the strength of the norm is a property of the group.

3.2.2. Dependent Variable: The Participation Behavior. Another dependent variable of the data analysis is the public sending of email answers. This study does not rely on selfreported assessments of the contribution behavior of the respondents. Rather, the participation behavior of the respondents was directly observed by reading the email messages that were sent to the mailing list during the observation period spanning two months.

Every email message of a respondent was coded as a question, an answer, or a different kind of message. If the email contained a request for information then it was coded as a "question". If an email contained a reaction to such a request for information then it was coded as an "answer". If neither coding was relevant then it was coded as "another kind of message." A small number of email messages contained both a question and an answer to another question. These messages were coded both as question and answer. In order to minimize the effects of a potential bias in the coding of the emails, the most interesting category of participation was measured by a dichotomous variable. A respondent was categorized as an "answer sender" if at least one of his sent emails was coded as an answer. As a consequence, the empirical analyses examine under which conditions researchers become active as senders of answers.

3.2.3. Independent Variables. Embeddedness of the emailing lists was measured with the help of an unfolding scale analysis (Van Schuur and Post, 1990) of five six-point Likertscaled items, which resulted in a Mudfold scale. The following five items had to be answered by those emailing list members who had been a member for at least one year and who had been active researchers for at least two years in a field related to the mailing list. ${ }^{6}$

"To what extent do the following statements describe adequately the group of researchers in your Mailing List "?" (a) It is more a group of unconnected individuals than a research community." "(b) It is a set of groups and cliques with their own interests and activities, but not much in common as a research community." “(c) It is a set of groups and cliques with their own interests and activities, but also some common interests as a research community." (d) It is a moderately integrated research community that shares some interests and some activities in common." " (e) It is a well-integrated research community that shares many interests and activities in common."

The results of the scale analysis showed that the items form a good unfolding scale. The coefficient of scalability is $H=.65$; none of the five items has a scalability value of $H<.55 .^{7}$ The embeddedness of the emailing list is indicated by the mean scale value of the mailing list members' scores on the Mudfold scale. 
3.2.4. Other Independent Variables. Details about the measurement of the theoretically interesting independent as well as other control variables can be found in Matzat (2001) Appendix 6.3. Here only the most crucial aspects of the measurements are dealt with.

As an indicator for the contribution costs the natural logarithm of the months of use of email is taken, which is inversely proportional to the time cost for a contribution. For the construction of the two interaction effects between email experience on the one hand and a high degree of embeddedness and a strong norm on the other hand, the embeddededness and the norm strength indicators are dichotomized. Each of them is multiplied with the indicator of the degree of email experience. The cut-off points for the dichotomizations are arbitrarily chosen such that the upper third of the groups is categorized as having a 'high' degree of embeddedness or as having a 'strong' norm.

The researcher's prominence is measured by a self-assessment based on a seven-point Likert-scaled item. The proportion of highly prominent members is measured by the group proportion of those members who scored five or higher on the scale.

\subsection{Descriptive Findings}

The members of the 49 selected academic mailing lists include not only active researchers, as Table 1 shows. The following tests only use the data of respondents who were actively involved in research activities.

Table 1. POSITION-What is your current main professional position?

\begin{tabular}{rlccc}
\hline & & Frequency & Valid percent & Cumulative percent \\
\hline Valid & & & \\
1 & Undergraduate student & 54 & 1.2 & 1.2 \\
2 & Ph.D. student (or comparable) & 841 & 18.8 & 20.0 \\
3 & Postdoc (or comparable) & 231 & 5.2 & 25.2 \\
4 & Assistant Prof. (or comparable) & 551 & 12.3 & 37.5 \\
5 & Associate Prof. (or comparable) & 538 & 12.0 & 49.5 \\
6 & Professor (or comparable) & 518 & 11.6 & 61.1 \\
7 & Other university researcher & 319 & 7.1 & 68.2 \\
8 Non-university researcher & 438 & 9.8 & $\mathbf{7 8 . 0}$ \\
9 Teacher & 61 & 1.4 & 79.3 \\
10 & Retired, but active in research & 59 & 1.3 & 80.7 \\
11 Retired, no research activity & 17 & .4 & 81.0 \\
12 & Other position & 849 & 19.0 & 100.0 \\
Total & 4476 & 100.0 & \\
Missing Values & 86 & & \\
Total & & 4562 & & \\
\hline
\end{tabular}


Of all the respondents, $70.8 \%$ are male and $29.8 \%$ are female. Of all the respondents, $34.7 \%$ had their main professional position in the USA, $22.3 \%$ in the UK, $5.2 \%$ in the Netherlands, $4.5 \%$ in Canada, $4.4 \%$ in Australia, $4.3 \%$ in Germany and 2.2\% in France. The large majority of the remainder of the researchers had their main professional position in another European or Asian country. The prevalent mother tongues of the respondents were US English (32.1\%), British English (28.0\%), Dutch (6.2\%), German (6.4\%), French (3.6\%), Spanish (3.6\%), Italian (2.4\%), and Russian (1\%). The 49 academic emailing lists include those dealing with topics of the social sciences, the natural sciences, the humanities and multidisciplinary topics.

The multivariate data analyses for testing the hypotheses include only the data of 47 lists. Two moderately small lists had to be excluded because of missing values. One of the included lists communicated in Dutch, while 46 of the lists communicated (mainly) in English. In one of the English speaking lists with a high message volume, 10 emails were posted in Spanish and were excluded from the data analysis.

In line with the findings of other empirical studies (see Zelman and Leydesdorff, 1999; Stegbauer and Rausch, 2001; Rost, 2001), only a minority of the respondents were active participants in the list discussions during the two months of observation, with $11.2 \%$ of them sending at least one email-message. The proportion of respondents who sent a question is $3.9 \%$ and the proportion who sent a public answer to a question is $5.2 \%$.

\section{Results}

\subsection{The Tests of the Hypotheses}

In this section the results of two different tests are shown. First, the test of Hypothesis 1 derived from the Coleman model on norm emergence is presented. Second, the hypotheses about the effects predicted by the reputation model are tested. These hypotheses include two predicted effects of the emergence of a help-prescribing norm. For the test of Hypothesis 1, the strength of the help-prescribing norm is the dependent variable. The second test includes norm strength as one independent variable among others that predict whether members of emailing lists become active as a sender of online answers during the group discussion.

The multivariate test of the Coleman model is based only on the answers of those respondents who had some background knowledge about the emailing list and its research community such that they were able to assess the norm strength (see Section 3.2 for the measurement). That is, the norm strength perceived by the individual is the dependent variable. The bivariate correlation between the embeddedness and the perceived norm strength shows that the higher the degree of embeddedness, the higher is the strength of the norm that the member perceives ( $r=0.32, p<0.01, N=1447)$. A two-level analysis of variance shows that the intra-class correlation of the perceived norm strength is 0.241 , meaning that $24.1 \%$ of the total variance in the perception of norm strength lies between groups $(N=1224, n$ [number of groups] $=47)$. The following Table 2 shows the multivariate test results of the Coleman model. The test is based on a two level linear regression analysis. The model presented in the second column of Table 2 controls for a number of other effects 
Table 2. The Coleman model: 2 level linear regression analysis of norm strength.

\begin{tabular}{|c|c|c|}
\hline Variable & $\begin{array}{l}\text { Model 1: Estimated } \\
\text { value (standard error) }\end{array}$ & $\begin{array}{l}\text { Model 2: Estimated } \\
\text { value (standard error) }\end{array}$ \\
\hline \multicolumn{3}{|l|}{ Group level effect } \\
\hline Embeddedness & $0.183^{* *}(0.056)$ & $0.118^{*}(0.051)$ \\
\hline \multicolumn{3}{|l|}{ Control variables } \\
\hline \multicolumn{3}{|l|}{ Group level effects } \\
\hline List questions & $0.016^{* *}(0.0051)$ & $0.303^{* *}(0.071)$ \\
\hline Mean membership duration & $-0.0055(0.012)$ & $0.005(0.012)$ \\
\hline Group size & - & $-0.00087(0.00054)$ \\
\hline Default reply to group & $0.613^{*}(0.335)$ & $0.67^{*}(0.33)$ \\
\hline \multicolumn{3}{|l|}{ Individual level effects } \\
\hline Pre-existing contacts & - & $0.113(0.082)$ \\
\hline Membership duration & $-0.000077(0.00008)$ & $-0.00005(0.00008)$ \\
\hline Prominence & - & $-0.024(0.055)$ \\
\hline Knowledge & $-0.0040(0.053)$ & $-0.093(0.059)$ \\
\hline Number of written papers & - & $0.01(0.026)$ \\
\hline Number of visited conferences & - & $-0.036(0.032)$ \\
\hline Male & - & $-0.26(0.17)$ \\
\hline Native speaker & - & $0.30^{*}(0.159)$ \\
\hline Years of research experience & - & $0.008(0.01)$ \\
\hline Member stayed in the list & - & $-0.08(0.15)$ \\
\hline Interruption in Access to list & - & $-0.06(0.15)$ \\
\hline Attachment to group & - & $0.453^{* *}(0.072)$ \\
\hline Self-efficacy & - & $0.163^{*}(0.070)$ \\
\hline Number of messages sent by researcher & - & $-0.023(0.033)$ \\
\hline Email experience & - & $-0.04(0.17)$ \\
\hline Importance of contacts & - & $0.097(0.064)$ \\
\hline Contacts in emailing list & - & $-0.033^{*}(0.015)$ \\
\hline${ }^{*}: p \leq .05^{* *}: p \leq .01$ (one-sided) & $\tau_{0}^{2}=0.555(0.19)$ & $\tau_{0}^{2}=0.55(0.18)$ \\
\hline$N=1224 n=47$ & $\sigma^{2}=6.23(0.26)$ & $\sigma^{2}=5.81(0.24)$ \\
\hline
\end{tabular}

$N$ : level 1 sample size (number of individuals); $n$ : level 2 sample size (number of groups); $\tau_{0}^{2}$ : level 2 variance of the intercept; $\sigma^{2}$ : level 1 error variance.

that might have influenced whether the group member regarded the emailing list to have a strong or weak help-prescribing norm (see Section 2).

The crucial result of the multivariate test is that, apart from other influence factors, the degree of embeddness has the predicted significant positive effect on the perceived norm strength. Apart from perceptions that may be dependent on the attitude toward the group, the list involvement and other individual 'nuisance' effects, the norm is regarded to be stronger 
for a higher degree of embeddedness. Indicators of the duration of group interaction, such as the individual or mean duration of membership, do not have a significant effect. The model, including all control variables, 'explains' $71.6 \%$ of the between-group variance and $6.9 \%$ of the level 1 error variance. Matzat (2001) provides additional analyses that strengthen the observed result.

Given that a higher degree of embeddedness of the list in a research community leads to the emergence of a help-prescribing norm, the price-theoretical reasoning of the reputation model can be tested by examining the effects of the emergence of a norm on the answering behavior. Table 3-Model 1 shows the univariate effect of norm strength on the likelihood to become active as a sender of email answers. Table 3-Model 2 shows a multivariate test of the two hypotheses of the reputation model with respect to the effects of norms and a test of the other six hypotheses about determinants of the sending of email answers. Model 2 includes the most crucial control variables. Moreover, Model 3 shows the test results of a model that additionally includes a larger number of control variables.

The following seven findings are the most important ones. First, the direct effect of norm strength on the likelihood to send email answers is significant only in the univariate model, but no longer in the multivariate model. ${ }^{8}$ Second, norm strength affects the likelihood to send email answers by mediating the effect of email experience. The interaction effect between email experience and norm strength is significant. That is, under the condition of a strong norm the effect of email experience is smaller than under the condition of a weak norm. This is in accordance with Hypothesis 9. Third, embeddedness shows the expected positive and significant effect. Fourth, emdeddedness mediates the effect of email experience. That is, under a condition of high embeddedness the effect of email experience is smaller than under a condition of low embededness. Fifth, email experience and the number of list contacts show the expected positive significant effects on the likelihood to send email answers. Sixth, neither prominence of the researcher nor the proportion of prominent researchers as members of the list show the expected effects. While the effect of prominence is nonsignificant, the effect of the proportion of prominent members is significant, but negative. Hypothesis 7 , however, predicted a positive effect. Seventh, the degree of interest in the exchanged information or the importance of making new contacts do not show any effect on the likelihood to send email answers.

\subsection{Interpretation of the Results}

The results provide evidence for Hypothesis 1 derived from the Coleman model on norm emergence. The higher the degree of embeddedness of the emailing list in a well-integrated research community, the stronger is the help-prescribing norm. The finding supports the assumption of the Coleman model that a high network density within a group facilitates the emergence of a norm.

Five out of the eight hypotheses of the reputation model find evidence. Most important, the results support the idea that the social embeddedness of the emailing list affects the communication behavior. The embeddedness has a direct and a mediating effect on the likelihood to send email answers. In combination with the finding that additionally a high degree of embeddedness affects the emergence of a help-prescribing norm, the 
Table 3. 2 level logistic regressions of provision of help/answers.

\begin{tabular}{|c|c|c|c|}
\hline Variable & $\begin{array}{l}\text { Model 1: Estimated } \\
\text { value (stand. error) }\end{array}$ & $\begin{array}{l}\text { Model 2: Estimated } \\
\text { value (stand. error) }\end{array}$ & $\begin{array}{l}\text { Model 3: Estimated } \\
\text { value (stand. error) }\end{array}$ \\
\hline \multicolumn{4}{|l|}{ Individual level effect } \\
\hline Email experience & - & $0.330 *(0.200)$ & $0.380 *(0.203)$ \\
\hline Prominence of sender & - & $0.099(0.074)$ & $0.118(0.080)$ \\
\hline Contacts in emailing list & - & $0.052^{* *}(0.019)$ & $0.047^{*}(0.020)$ \\
\hline \multicolumn{4}{|l|}{ Group level effects } \\
\hline Embeddedness & - & $0.163^{*}(0.093)$ & $0.162 *(0.093)$ \\
\hline Norm strength & $0.72^{* *}(0.09)$ & $0.237(0.24)$ & $0.248(0.247)$ \\
\hline $\begin{array}{l}\text { Proportion of highly } \\
\text { prominent members }\end{array}$ & - & $-10.15^{* *}(2.66)$ & $-9.71^{* *}(2.68)$ \\
\hline \multicolumn{4}{|l|}{ Cross level interaction effects } \\
\hline Strong norm $\times$ email experience & - & $-0.154^{*}(0.09)$ & $-0.20^{*}(0.09)$ \\
\hline $\begin{array}{l}\text { High embeddedness } \times \text { email } \\
\text { experience }\end{array}$ & - & $-0.14(0.09)$ & $-0.150^{*}(0.089)$ \\
\hline \multicolumn{4}{|l|}{ Control variables } \\
\hline \multicolumn{4}{|l|}{ Group level effects } \\
\hline Group size & - & $-0.0014^{* *}(0.0006)$ & $-0.0016^{* *}(0.00056)$ \\
\hline List questions & - & $0.234^{* *}(0.09)$ & $0.26^{* *}(0.10)$ \\
\hline Default reply to group & - & $0.88^{*}(0.35)$ & $0.830^{*}(0.35)$ \\
\hline \multicolumn{4}{|l|}{ Individual level effects } \\
\hline Importance of contacts & - & - & $0.10(0.09)$ \\
\hline Information interest (reciprocity) & - & - & $0.168(0.110)$ \\
\hline Knowledge & - & $0.166^{*}(0.077)$ & $0.135^{*}(0.079)$ \\
\hline Years of research experience & - & $0.0227 *(0.0135)$ & $0.023 *(0.014)$ \\
\hline Interruption in Access to list & - & $-0.464^{*}(0.220)$ & $-0.47^{*}(0.22)$ \\
\hline Number of written papers & - & - & $0.054(0.033)$ \\
\hline Male & - & - & $0.67^{* *}(0.25)$ \\
\hline Non-university researcher & - & - & $0.26(0.31)$ \\
\hline Other university researcher & - & - & $0.586^{*}(0.344)$ \\
\hline Professor & - & - & $-0.11(0.30)$ \\
\hline Native speaker & - & - & $0.416^{*}(0.23)$ \\
\hline Number of visited conferences & - & - & $-0.059(0.06)$ \\
\hline $\begin{array}{ll}*: p \leq .05^{* *}: p \leq .01 \text { (one-sided) } \\
N=2466 & n=47\end{array}$ & $\tau_{0}^{2}=0.06(0.07)$ & $\tau_{0}^{2}=0.010(0.046)$ & $\tau_{0}^{2}=0.0000(0.0000)$ \\
\hline
\end{tabular}

$N$ : level 1 sample size (number of individuals); $n$ : level 2 sample size (number of groups); $\tau_{0}^{2}:$ level 2 variance of the intercept.

The first interaction variable is defined as the product of the email experience index with the dichotomous 'embeddedness' variable $(0=$ no high embeddedness, $1=$ high embeddedness $)$. The second interaction variable is defined as the product of the email experience index with the dichotomous 'norm strength' variable $(0=$ no strong norm, 1 = strong norm). 
results underline the importance of the influence of the social embeddedness of an emailing list.

For the unexpected positive effect of the proportion of highly prominent members I offer the following two potential explanations. First, it might be the case that members feel inhibited when the list membership includes a high proportion of very prominent researchers. In this case, researchers are concerned about their reputation in the academic community, just as the reputation model implies. Apparently, the assumption that in such an emailing list there are additional opportunities for the average member to gain reputation is wrong. Contrary to this assumption, in a list with a high proportion of very prominent researchers, members fear losing a measure of reputation through inappropriate answers. This reasoning thus assumes an inhibiting effect of the presence of prominent members. Second, it might be the case that 'ordinary' members of an emailing list with a high proportion of very prominent members expect the more prominent members to answer the incoming questions. This reasoning assumes a kind of bystander effect caused by a high proportion of very prominent researchers. Bystander effects have been found in chat groups of a very large size (see Markey, 2000).

It is not quite clear why the expected effect of the prominence of the researcher does not show up. It might be that the used indicator for the researcher's endowment with reputation, namely a self-assessment, is not a valid one.

The underlying interpretation of the found effects is that researchers are under some conditions motivated to send email answers because it gives them some reputation within the academic community. Could alternative theories explain the found pattern of effects? It might be that researchers are motivated to contribute to discussions because they want to facilitate the making of new contacts in bilateral communication. However, this interpretation of the findings faces the problem that those researchers for whom the making of contacts is more important are not more likely to send email answers. ${ }^{9}$ Still another hypothesis would be that researchers are motivated by a hope for reciprocity (Thorn and Connolly, 1987). According to this hypothesis group members contribute because they hope that their contribution will induce others to reciprocate. However, this hypothesis faces the problem that those with a larger interest in the information are not more likely to send email answers.

Other potential explanations of why members could contribute, such as having feelings of being attached to the group cannot explain the found pattern of significant effects. Therefore I regard the theory underlying the reputation model -namely that researchers are motivated to contribute answers because they hope to gain reputation- as the most plausible theory that can explain the findings.

\section{Summary and Conclusions}

This paper analyzes two questions. First, under which conditions does a norm emerge in academic online groups that prescribes that members should provide online answers to the questions of other members during online discussions? Second, what effects does such a norm, and other social conditions, have on the contributing behavior of researchers during online discussions? 
The Coleman model of norm emergence (Coleman, 1990) is used to answer the first question. The reputation model is used to answer the second one. According to the Coleman model groups with a dense network among the members have a higher chance of developing a norm. If an action of group members has similar positive consequences for other members and if there is no opportunity for bilateral exchange then a demand for a norm that prescribes this behavior would arise. The norm would be realized if members can solve the secondorder free rider problem of employing positive or negative sanctions for norm compliance.

As a consequence, it is expected that emailing lists that are embedded in a well-integrated research community have a higher likelihood of developing a norm that prescribes members to provide email answers to other co-members during online discussions than emailing lists without any embeddedness.

The reputation model is utilized to predict the effects of such a norm. According to the reputation model researchers are motivated to provide email answers during online discussions under some conditions because they can gain reputation within the academic community by doing so. The model leads to a number of predictions about conditions favoring the provision of email answers during online discussions. It is expected that members in emailing lists with a high degree of embeddedness and lists with a strong help-prescribing norm are more likely to provide email answers than members in an emailing list with a low degree of embeddedness or a weak norm. Moreover, the effect of email experience should be mediated by the degree of embeddedness and by the strength of the norm. For example, in lists with a strong norm, the effect of email experience on the likelihood to send email answers should be smaller than in emailing lists with a weak norm.

The results of the multivariate data analyses provide evidence for the hypothesis of the Coleman model. The higher the degree of embeddedness of an emailing list the stronger is a help-prescribing norm. Moreover, there is evidence for five out of eight hypotheses derived from the reputation model. Members of emailing lists with a high degree of embeddedness are more likely to contribute to the online discussion by sending email answers. The strength of the help-prescribing norm has the expected mediating effect on the likelihood to provide email answers. However, no evidence was found for a direct effect of norm strength.

It is argued that the found effects can best be explained with the assumption of the reputation model that the sending of email answers is stimulated by conditions that give researchers opportunities to gain reputation by sending answers. Alternative explanations that rely on different motivations cannot explain the pattern of found effects and run into other problems.

The results underline the significance of a high degree of social embeddedness of academic mailing lists. A high degree of embeddedness has a number of effects that are important for theoretical and practical reasons, since they provide solutions to problems of knowledge management. Embeddness has a direct and a mediating effect on the likelihood to send email answers. Additionally, it has an indirect effect since it facilitates the emergence of a help-prescribing norm that affects the provision of email answers.

The analyses also offer answers to two questions that are of general interest in the field of internet research. First, studies of online groups often show that certain desirable outcomes for the members, such as a useful exchange of information (Constant et al., 1996; Cothrel and Williams, 1999) or the development of a community (Baym, 1993), 
are in principal possible. However, it is unknown on which institutional conditions the realization of desirable outcomes depends (DiMaggio et al., 2001). This study points to an important institutional conditions, namely the embeddedness of an online group in an offline community, that affects the likelihood of realizing some desirable outcomes, such as cooperative norms and the effective provision of help by members.

Second, in the field of internet research it is argued that offline relations affect online interaction (Wellman, 1997; Wellman and Gulia, 1998). However, it is unclear how this happens. This study provides mechanisms by which offline networks influence online interaction via direct and indirect paths and presents empirical evidence for their validity.

The insights of the study could provide guidance for the analysis of the social consequences of the internet (Kraut et al., 1998, 2002) in general, and the analysis of online groups in particular. They show that the impact of the internet depends on social conditions. Research on the social impact of the internet should thus study the governance of online groups as a way of shaping the internet and its consequences.

The analysis of online groups would profit very much from studying their governance structure. Which kinds of incentives do motivate members to become active in online discussions? Which conditions makes sure that the adequate incentives are provided? These questions are relevant for different kinds of online groups that exchange knowledge. They are also relevant for online groups that are built up to facilitate the provision of social support. For reaching the potential of ICT it is important to find out more about institutional conditions that affect their outcome. I argue that a high degree of social embeddedness of online groups in offline networks is an important condition that affects the outcomes of different kinds of online groups. The crucial point is that a high degree of social embeddedness does not mean that all members have offline relations with each other. Rather, if there exists a well-integrated subgroup then the whole online group may profit from it. For example, online groups for seniors might profit if within the whole online group there exists an active minority of members who know each other via meetings of a nation-wide association for seniors.

It is no longer realistic to assume that the internet or ICT in general will have desirable outcomes for the people. However, the analysis of the governance structure of online groups and institutional conditions that affect their outcomes might be a promising way for getting more out of the potential of ICT and the internet for humans and society.

\section{Acknowledgments}

Parts of the paper were presented at the international conferences German Online Research 2002 and Internet Research 4.0. I would like to thank Tom Snijders and Henk de Vos (both University of Groningen) for helpful comments on the data analyses and the design of the study. Melanie Reddig (University of Duesseldorf) helped improving the manuscript by thoughtful comments.

\section{Notes}

1. See Matzat (2001) for the inclusion of other subgoals in the model.

2. In Becker's (1976) original theory of interaction " $x$ " indicates a good. Here it is used as an indicator for an activity (basket) that produces utility. 
3. A 50th selected mailing list had to be excluded because its manager at short notice decided to stop with the managing activities and did not provide the necessary email addresses.

4. The $p$-values presented in the multivariate analyses are one-sided $p$-values, unless otherwise mentioned.

5. The results of the Mokken scale analysis showed that these three six-point-items can be used to construct a scale that fulfils the pre-conditions and assumptions of a Mokken scale to a very high degree [see Matzat (2001)-Appendix 6.1 for details of the Mokken scale analysis]. The $H$-coefficient of the scalability of all three items is $H=.57$; none of the three items has a scalability value of $H<.55$. The estimated reliability of the whole scale is rho $=.78$. These numbers justify speaking of a 'strong' scale.

6. The idea of an unfolding scale analysis is that a number of items and persons can be ordered unidimensionally with regard to one latent trait (in this case: the perceived degree to which a group constitutes an integrated research community that shares many interests and activities in common). The items can be ordered according to the degree of integration they express and the persons can be ordered according to the degree of integration that they perceive. The smaller the distance between the item and the person on the one dimension (perceived respective expressed degree of group integration), the larger the probability of there being a positive answer to the item from the respondent. All items had to be assessed on a six-point Likert scale with answering options ranging from "disagree completely" to "agree completely". The items uni-dimensionally cover a wide range of the degree to which the group of researchers in the mailing list constitutes an integrated research community that shares many interests and activities in common.

7. The assumption underlying the measurement procedure is that the more the group of researchers in the mailing list constitutes an integrated research community that shares many interests and activities in common, the higher is the degree of network embeddedness, which consists of the frequency of the members' social interaction outside of the online group. The reader can find details of the Mudfold scale analysis in Matzat (2001). In addition, evidence is presented for the assumption that the higher the degree of integration, the higher is the frequency of member interaction outside of the group.

8. This finding differs from the finding presented in Matzat (2001), because here the square root of the number of list questions is taken as a control variable. The result cannot be explained by multicollinearity. The correlation between embeddedness and norm strength is $r=0.34(n=47)$.

9. Additional analyses presented in Matzat (2002) show that this alternative theory does not find any evidence.

\section{References}

Baumol, W.J. (1977), Economic Theory and Operations Analysis. Prentice/Hall international.

Baym, N.K. (1993), "Interpreting Soap Operas and Creating Community: Inside a Computer-Mediated Fan Culture," Journal of Folklore Research, 30, 143-176.

Becker, G.S. (1976), "A Theory of Social Interactions," in G.S. Becker (Ed.) The Economic Approach to Human Behavior. The University of ChicagoPress, Chicago and London, pp. 253-281.

Blau, P.M. (1955), The Dynamics of Bureaucracy. The University of Chicago Press, Chicago, London.

Blau, P.M. (1964), Exchange and Power in Social Life. John Wiley \& Sons, New York, London, Sidney.

Coleman, J.S. (1990), Foundations of Social Theory. Cambridge, Harvard University Press.

Constant, D., L. Sproull and S. Kiesler (1996), "The Kindness of Strangers: The Usefulness of Electronic Weak Ties for Technical Advice,” Organization Science, 7, 119-135.

Constant, D., S. Kiesler and L. Sproull (1994), "What's Mine is Ours, or is it? A Study of Attitudes About Information Sharing," Information Systems Research, 5, 400-421.

Cothrel, J. and R. Williams (1999), "Online Communities: Getting the Most Out of Online Discussion and Collaboration," Knowledge Management Review, 1, 20-25.

Cummings, J., B. Butler and R. Kraut (2002), "The Quality of Online Social Relationships," Communications of the ACM, 45, 103-108.

DiMaggio, P., E. Hargittai, W.R. Neuman and J.P. Robinson (2001), “Social Implications of the Internet," Annual Revue of Sociology, 27, 307-336.

Ekeblad, E. (2001), The Emergence and Decay of Multilogue. Self-Regulation of a Scholarly Mailing List. [Online]. Available: http://hem.fyristorg.com/evaek/writings/earli99/multdyn.html 
Herring, S.C. (1999), “The Rhetorical Dynamics of Gender Harrassment On-Line,” The Information Society, 15, $151-167$.

Hirshleifer, J. and A. Glazer (1992), Price Theory and Applications. Englewood Cliffs, Prentice Hall.

Horrigan, J.B. (2001), “Online Communities: Networks that Nurture Long-Distance Relationships and Local Ties. [On-line]. Available: http://www.pewinternet.org

Kollock, P. (1998), “The Economies of Online Cooperation: Gifts and Public goods in Cyberspace," in M. Smith and P. Kollock (Eds.) Communities in Cyberspace. Routledge, London, pp. 220-239.

Kraut, R., M. Patterson, V. Lundmark, S. Kiesler, T. Mukopadhyay and W. Scherlis (1998), "Internet Paradox: A Social Technology That Reduces Social Involvement and Psychological Well-Being?" American Psychologist, 53, 1017-1031.

Kraut, R., S. Kiesler, B. Boneva, J. Cummings, V. Helgeson and A. Crawford (2002), "Internet Paradox Revisited," Journal of Social Issues, 1, 49-74.

Lewenstein, B.V. (1995), "Do Public Electronic Bulletin Boards Help Create Scientific Knowledge? The Cold Fusion Case," Science, Technology, \& Human Values, 123-149.

Lindenberg, S. (1986), "The Paradox of Privatization in Consumption,” in A. Diekmann and P. Mitter (Eds.) Paradoxical Effects of Social Behaviour. Essays in Honor of Anatol Rappoport. Physica Verlag, Wien, pp. 297-310.

Markey, P.M. (2000), "Bystander Intervention in Computer-Mediated Communication," Computers in Human Behavior, 16, 183-188.

Matzat, U. (2001), Social Networks and Cooperation in Electronic Communities: A Theoretical-Empirical Analysis of Academic Communication and Internet Discussion Groups. Amsterdam, Thela Publishers. [Also at: http://www.ub.rug.nl/eldoc/dis/ppsw/u.matzat/]

Matzat, U. (2002), "The Embeddedness of Academic Internet Groups in Social Networks: Reputation Effects or Incentives for the Creation of Contacts?" Under review.

Matzat, U. (2004), "Academic Communication and Internet Discussion Groups: Transfer of Information or Creation of Social Contacts?," Social Networks, 26(3), 221-255.

McLure Wasko, M. and S. Faraj (2000), ““'It is What One Does”: Why People Participate and Help Others in Electronic Communities of Practice," Journal of Strategic Information Systems, 155-173.

Mokken, R.J. (1997), "Nonparametric Models for Dichotomous Responses," in W.J.v.d. Linden and R.K. Hambleton (Eds.) Handbook of Modern Item Response Theory. Springer, New York etc., pp. 351-367.

Molenaar, I.W. (1997), "Nonparametric Models for Polytomous Responses," in W.J.v.d. Linden and R.K. Hambleton (Eds.) Handbook of Modern Item Response Theory. Springer, New York etc., pp. 369-380.

Rost, M. (2001), Mailing Lists und ihre Strukturen. [On-line]. Available: http://www.netzservice.de/Home/ maro/home/mlstudie10.zip

Snijders, T.A.B. and R.J. Boskers (1999), Multilevel Analysis: An Introduction to Basic and Advanced Multilevel Modeling. Sage London, etc..

Stegbauer, C. and A. Rausch (2001), "Die schweigende Mehrheit-“Lurker" in internetbasierten Diskussionsforen," Zeitschrift fuer Soziologie, 30, 48-64.

Thorn, B.K. and T. Connolly (1987), "Discretionary Data Bases: A Theory and Some Experimental Findings," Communication Research, 14, 512-528.

Van Schuur, W. and W.J. Post (1990), Mudfold User's Manual. Groningen: iec ProGAMMA.

Walther, J.B. (1996), “Computer-Mediated Communication: Impersonal, Interpersonal, and Hyperpersonal Interaction," Communication Research, 23, 3-44.

Wellman, B. (1997), “An electronic Group is Virtually a Social Network," in S. Kiesler (Ed.) Culture of the Internet New Jersey, pp. 179-205.

Wellman, B. and M. Gulia (1998), "Net Surfers don’t Ride Alone: Virtual Communities as Communities," in P. Kollock and M. Smith (Eds.) Communities in Cyberspace. University of California Press, Berkeley, pp. 163-190. Zelman, A. and L. Leydesdorff (1999), "Threaded Email Messages in Self-Organization and Science \& Technology Studies Oriented Mailing Lists," Scientometrics, 48, 361-380.

Uwe Matzat (Ph.D.) is Assistant Professor of Sociology at Eindhoven University of Technology, the Netherlands. His research interests include the analysis of online groups and the social impact of the internet. 